\title{
Optimal positioning of groundwater supply wells in residential areas with uncertain information ${ }^{\dagger}$
}

\author{
R.A.R. Prabodanie* \\ Department of Industrial Management, Faculty of Applied Sciences, Wayamba University of Sri Lanka, Kuliyapitiya.
}

Revised: 27 July 2015; Accepted: 29 September 2015

\begin{abstract}
A simulation-optimisation based methodology has been proposed for identifying economically and ecologically optimal locations for new groundwater supply wells. The purpose of optimisation was to find cost effective extraction locations with a minimum possibility of getting contaminated or drying out within a reasonable time period. A simulation model developed with MODFLOW (modular threedimensional finite-difference groundwater flow model) and MT3DMS (modular three dimensional multispecies transport model) was used to determine the spatiotemporal effects of potential pollution sources and water withdrawals. Monte Carlo method was used with the simulation models to incorporate the uncertainty in the behaviour of potential pollution sources and water extractions. This integrated methodology was illustrated using a small hypothetical case study. The results indicate that readily invisible hydro-geological factors such as heterogeneous characteristics of subsurface strata, irregular gradients, and varying aquifer thickness have a significant influence on the sustainability of a water supply well. The well positioning decisions recommended by the proposed model can be explained and justified based on scientific data. It finds potentially feasible and sustainable locations for new water supply wells, given uncertain information on future events. Since the uncertainty of available information is taken into account, this methodology is suitable for locating wells in poorly understood aquifers utilised for residential supply. The same methodology can be used to determine landfill locations, minimising negative environmental impacts.
\end{abstract}

Keywords: Extraction, groundwater, optimisation, simulation, well location.

\section{INTRODUCTION}

Groundwater is the primary source of domestic water supply in Sri Lanka. About $80 \%$ of the island's rural drinking water comes from residential open dug wells and tube wells (Panabokke \& Perera, 2005). Groundwater is usually considered as safe for drinking and as reliable in supply. However, recent developments in the country have posed significant threats to the safety of groundwater. Mainly, the use of groundwater for domestic, industrial, and agricultural purposes has been intensified in the recent years (Panabokke, 2001; IWMI, 2005). Together with intensive utilisation, instances of groundwater contamination have also been reported frequently (Mageswaran \& Mahalingam, 1983; Nanthini et al., 2001; Panabokke \& Perera, 2005; Bandara \& Hettiarachchi, 2010; Rodrigo, 2013).

Since Sri Lankan aquifers are relatively shallow, they are quite susceptible to contamination (IWMI, 2005) from potential sources such as agricultural land, soakage pits and waste landfill sites. With the increased demand for houses and limited availability of land, positioning of water supply wells outside the vicinity of contamination will be more difficult in the future. Since public sewage disposal systems are not available in most areas of Sri Lanka, sewage is disposed at the point of generation using domestic soakage pits. In highly residential areas, both water supply wells and soakage pits are located within the small block of land, in the neighbourhood of several other domestic soakage pits, water supply wells, and sometimes other sources of pollution such as waste landfill sites and industrial wastewater sumps. New wells are usually located based on conventional knowledge and architectural concerns, ignoring the potential for contamination. Simple restrictions such as maintaining a minimum distance between a water supply well and a soakage pit cannot guarantee the safety of groundwater, owing to the complex hydrological

\footnotetext{
"ranga.prabodanie@yahoo.com

${ }^{\dagger}$ An abstract based on the initial outcomes of this research has been presented at the $17^{\text {th }}$ International Forestry and Environment Symposium, held on 16 - 17 November, 2012 at Pegasus Reef Hotel, Handala, Wattala, Sri Lanka.
} 
processes that determine the directions of groundwater flow. In addition, water availability (potential yield) and other environmental concerns such as salt water intrusion should be considered in locating new wells, particularly if the aquifer is heavily utilised. Among the consequences of ignoring these environmental concerns are contamination of drinking water, drying out of wells during droughts, health risks associated with abandoned wells, and even conflicts related to water shortages (Mageswaran \& Mahalingam, 1983; Liyanage et al., 2000; Bandara \& Hettiarachchi, 2010; Fazlulhaq, 2012; Rodrigo, 2013).

This paper focuses on the problem of positioning groundwater supply wells in residential areas where groundwater is at the risk of getting polluted and/ or depleted. Proper scientific methods integrating groundwater science and optimisation are required to identify well locations accounting for the above mentioned hydrogeological processes, which are not trivial. The objective of the work presented in this paper is to develop a methodology to locate groundwater supply wells in the neighbourhood of potential pollution sources and other water supply wells, minimising the likelihood of getting contaminated or drying out.

Among several groundwater management issues, positioning of groundwater extraction wells is a problem associated with various objectives. Extraction wells are sometimes positioned for the purpose of remediation by extracting the polluted water with a minimum cost and minimum negative impacts on the environmental equilibrium (Chang et al., 1992; Ratzlaf et al., 1992; Wang \& Ahlfeld, 1994; Chu et al., 2005; Ko et al., 2005; Prasad $\&$ Mathur, 2008). In some cases, wells are located for the purpose of monitoring and detection of groundwater contamination in a cost efficient manner (Datta \& Dhiman, 1996; Storck et al., 1997; Yenigul et al., 2006; Chadalavada et al., 2010). In this paper, groundwater extraction for drinking and sanitation purposes was considered. Various optimisation methodologies with various objectives and constraints have been proposed for the purpose of positioning such water supply wells.

Mayer et al. (2002) and Fowler et al. (2004) modelled the well positioning problem with the objective of minimising the cost of installing and operating a set of extraction wells. They used an optimisation model to determine the well locations and abstraction rates subject to constraints on the net extraction rates, pumping rates, and hydraulic heads. Fowler et al. (2004) went a step further by solving these problems using the US geological survey modular groundwater model (MODFLOW) to simulate groundwater flow and an implicit filtering algorithm to solve the optimisation problem. Hsiao and Chang (2002) used a genetic algorithm (GA) integrated with constrained differential dynamic programming (CDDP) to determine the optimal number and locations of pumping wells considering the (location-dependent) fixed costs of installing wells and time-varying pumping rates.

Salt water intrusion problem has also been considered in selecting optimal well locations, particularly in coastal aquifers. Park and Aral (2003) proposed a multi-objective optimisation model to determine the optimal pumping rates and well locations, which meet a set of constraints on salt water intrusion and required extraction rates. Silva and Haie (2007) used an evolutionary algorithm linked with a simulation model to find the optimal locations of groundwater withdrawals in coastal aquifers. The proposed optimisation model finds the best well locations taking into account the demand for water, the cost of installing and operating the water supply network, and environmental constraints on salt water intrusion. Rao and Manju (2007) developed a linked simulation-optimisation model to find the optimal locations of pumping wells from a pre-determined set of candidate well locations so as to minimise the salinity concentration in pumped water.

In addition to optimisation methods, GIS based methodologies have also been proposed for positioning groundwater extraction wells. Razowska-Jaworek (2010) proposed the use of GIS analysis for positioning public water supply wells. Both hydro-geological parameters and economic factors have been considered in this study. Al-Daghastani and Al-Maitah (2006) have also used GIS techniques to locate groundwater wells based on catchment topography and drainage patterns.

The literature is rich with a variety of methodologies proposed for optimal positioning of groundwater supply wells taking into account the associated costs and the spatiotemporal effects of extractions. However, factors such as the variations in water withdrawals and pollutant loadings, and the potential for contamination of well water in the future are yet to be incorporated into those methodologies. Better and more sophisticated methodologies have also been proposed for locating groundwater monitoring wells and remediation wells (Storck et al., 1997; Yenigul et al., 2006; Mantoglou \& Kourakos, 2007). These well selection models have utilised the Monte Carlo method to internalise the uncertainties in the model parameters. Such probabilistic approaches are applicable in cases of poorly understood groundwater systems with little knowledge on future stresses. Similar approaches can also be adopted and utilised for locating groundwater supply wells. 
This paper proposes a new methodology for finding economically and ecologically optimal locations for groundwater supply wells taking into account the potential pollution sources, water withdrawals, and possible variations in pollutant loading and water withdrawals. First, a set of potential extraction locations (candidate wells) were identified together with rough estimates of installation and operation costs. Potential pollution sources and existing wells were also identified, but the exact estimates of their characteristics are not required. Possible impacts of water extraction from each candidate location (i.e., the resulting head and concentration distributions at the extraction locations and other control points) were obtained from groundwater flow and solute transport simulations. Monte Carlo method was used to incorporate the uncertainty in pollutant loading from potential sources and water withdrawal rates from existing wells. The estimated head and concentration distributions then served as the main input to an optimisation model, which was formulated to find the least cost extraction locations subject to constraints on the likelihoods of getting contaminated, getting dried out, drying out other neighbouring wells, and having other negative impacts such as salt water intrusion into the aquifer. The idea was demonstrated using a small hypothetical case study, and its applicability for a real world problem was illustrated. The results indicated the importance of using simulation-optimisation based methods in locating groundwater extraction wells, particularly in heavily utilised aquifers, which are more susceptible to pollution. Since the uncertainty in the input parameters were internalised using the Monte Carlo method, the proposed methodology is suitable for locating wells in poorly understood aquifers as well.

\section{METHODOLOGY}

This paper addresses the problem of selecting least cost groundwater extraction locations with an acceptable level of confidence that the wells will not get contaminated or dried out within a reasonable time period. The key factors considered were, the water availability at potential well locations, potential sources of pollution, and the effects of extractions from each potential well location on other environmental control points.

In the developed well positioning methodology, a set of candidate well locations were first selected. The extraction rates (for both existing and proposed wells) and leakage rates from the potential pollution sources were considered as uncertain parameters with known probability distributions. If historical data is available, probability distributions can be fitted using a widely available software such as MATLAB. For example, the extraction rates can be assumed as normal distributions with known means and standard deviations. For potential point sources like soakage pits with uncertain leakage rates, uniform distributions can be assumed (allowing for negligible and higher leakage rates). Similarly, suitable probability distributions can be assigned for diffuse sources such as landfill sites with uncertain rates of effluent leaking. Aquifer parameters and initial conditions may be considered as fixed or probabilistic parameters.

Groundwater flow and solute transport simulation models were used to estimate the spatiotemporal impacts of water extractions from potential well locations and pollutant loading from potential sources. MODFLOW (Harbaugh et al., 2000) and MT3DMS (Zheng \& Wang, 1999) codes were used for simulation. The simulation models were iteratively executed with random realisations of source loading rates and water extraction rates to obtain the probability distributions of heads and concentrations at a set of interested locations (candidate well locations and other control points). This approach of estimating the distribution of an uncertain variable is usually known as the Monte Carlo method (Winston, 1994).

An optimisation model was then formulated using the probability distributions of heads and concentrations to find the least cost well locations subject to constraints on, (1) the probability that the concentration in a selected well or at a concentration control point exceeds a prespecified threshold level, (2) the probability that a selected well will dry out or the head at a selected well location drops below a pre-specified level, and (3) the probability that the head at a head control point drops below a pre-specified level (to avoid salt water intrusion, to maintain river flows, etc.).

\section{Groundwater flow and transport model}

The partial differential equation which describes the fate and transport of a contaminant in a three-dimensional transient groundwater flow system is given as:

$$
\frac{\partial(\theta C)}{\partial t}=\frac{\partial}{\partial x_{i}}\left(\theta D_{i j} \frac{\partial C}{\partial x_{j}}\right)-\frac{\partial}{\partial x_{i}}\left(q_{i} C\right)+\sum_{s} q_{s} C_{s}+\sum_{n} R_{n}
$$


where $C=$ dissolved concentration $\left(\mathrm{gm}^{-3}\right), x_{i}=$ distance along the respective cartesian coordinate axis (m), $i, j=$ coordinate directions, $t=$ time (s), $q_{i}=$ Darcy velocity in the direction $i\left(\mathrm{~ms}^{-1}\right), \theta=$ porosity (dimensionless), $q_{s}=$ source/sink flow rate $\left(\mathrm{s}^{-1}\right), C_{s}=$ source concentration $\left(\mathrm{gm}^{-3}\right), D_{i j}=$ components of the dispersion tensor $\left(\mathrm{m}^{2} \mathrm{~s}^{-1}\right)$,

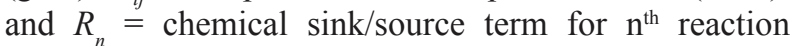
(Zheng \& Bennett, 2002). The transport equation is related to the groundwater flow equation through the Darcy’s Law (Zheng \& Bennett, 2002).

The MODFLOW code (Harbaugh et al., 2000) solves the standard groundwater flow equations and determines the flow terms, which are then used by the MT3DMS code (Zheng \& Wang, 1999) to simulate contaminant transport in groundwater using the above equation.

\section{Monte Carlo method}

In most of the field scale groundwater management problems, the exact values of the aquifer properties and the characteristics of external sources and sinks are not known. Hence, the Monte Carlo simulation method is adopted to solve the groundwater flow and solute transport models several times using input parameters drawn from random fields and to generate probability distributions of heads and concentrations.

For each candidate well location, a Monte Carlo simulation of groundwater flow and transport was carried out with a sufficient number of parameter realisations to estimate the probability distributions of concentrations and heads at the candidate wells and control points. MS excel was used as a front-end to generate random numbers, to run MODFLOW and MT3DMD simulations iteratively, and also to approximate the probability distributions. The estimated probability distributions then serve as the main input for the optimisation model.

\section{Optimisation model}

The goal of the optimisation model is choosing the best extraction locations to supply a fixed quantity of water at the minimum cost of installation and operation. Each well location has associated head and concentration distributions for the well location itself and for each control point. The optimal locations are to be selected subject to probabilistic constraints (usually known as chance constraints) on heads and concentrations at the well itself and at the control points. The head control points can be at existing water supply wells to avoid drying out; on the river banks to maintain sufficient stream flow and to avoid surface water flow into the aquifer; or in case of coastal aquifers, along the shore to avoid salt water intrusion. The concentration control points can also be at existing well locations or on river banks.

The cost of installing and operating a well at a given location may be affected by the cost of purchasing land (in case of a public well), digging and constructing, installing the distribution network, and treatment of water if required. In many real world situations, the cost terms will be endogenous as they will be determined by the distances between well locations and demand locations, depth to water (which affect the cost of digging and pumping), and concentrations (i.e. if the concentration is high, some treatment will be required incurring the cost of treatment). All these factors should be considered in assigning cost terms to candidate well locations. To minimise the total cost, the objective function of the optimisation model is formulated as:

$\operatorname{Min} \sum_{i} C_{i} x_{i}$

where $x_{i}$ is a binary decision variable indicating whether the candidate well location $i$ is selected (a value of 1 indicates selection) and $C_{i}$ is the total (discounted) cost of installing and operating an abstraction well at location $i$ during the planning period.

The solution algorithm would set $x_{i}$ to 1 for those well locations having the smallest $C_{i}$ subject to the following constraint on the maximum number of wells to be installed.

$$
\sum_{i} x_{i}=N^{M x}
$$

where $N^{M x}$ is the number of new wells to be installed.

Well location $i$ should be selected $\left(x_{i}=1\right)$ only if the associated probability that it would get dry during the planning period (probability that the head at well location $i$ drops below a certain level) is below a pre-specified level.

$x_{i} \operatorname{Pr}\left(h_{i} \leq H_{i}^{M n}\right) \leq P_{i}^{h}$ for all $i$

where $h_{i}$ is a random variable taking the value of the head at potential well location $i, H^{M n}$ is the minimum head level required at location $i$, and $P^{h}{ }_{i}$ is the maximum allowable probability of this head constraint violation relative to the required confidence level. 
In this formulation, constraints on heads and concentrations are imposed at the end of the planning (simulation) period assuming that the pollutant loading and water withdrawals occur continuously during the period. But these constraints can be imposed temporally at discrete time intervals if required.

Well location $i$ should be selected $\left(x_{i}=1\right)$ only if the associated probability that it would get contaminated (probability that the concentration at well location $i$ exceeds the maximum acceptable level) is below a prespecified level.

$x_{i} \operatorname{Pr}\left(c_{k i} \geq C_{k}^{M x}\right) \leq P_{k i}$ for all $i$ and $k$

where $c_{k i}$ is a random variable taking the value of the concentration of constituent $k$ at candidate location $i$ in the presence of a well there, $C^{M x}{ }_{k}$ is the maximum acceptable concentration of constituent $k$, and $P_{k i}$ is the maximum allowable probability of constraint violation relative to the required confidence level.

Well location $i$ should be selected $\left(x_{i}=1\right)$ only if the associated probability, that the head at any head control location (indexed by $m$ ) drops under the required minimum, is below a pre-specified level.

$x_{i} \operatorname{Pr}\left(h_{m i} \leq H_{m}^{M n}\right) \leq P_{m}^{h}$ for all $m$

where $h_{m i}$ is a random variable taking the value of the head at control point $m$ in the presence of a new well at location $i, H_{m}^{M n}$ is the minimum head level required at control point $m$, and $P_{m}^{h}$ is the maximum allowable probability of head constraint violation (relative to the required confidence level).

Well location $i$ should be selected $\left(x_{i}=1\right)$ only if the associated probability, that the concentration of any simulated constituent at any concentration control point (indexed by $n$ ) exceeds the threshold, is below a prespecified level.

$x_{i} \operatorname{Pr}\left(c_{k n i} \geq C_{k}^{M x}\right) \leq P_{k n}$ for all $k$ and $n$

where $c_{k n i}$ is a random variable taking the value of the concentration of constituent $k$ at control point $n$ in the presence of a well at location $i, P_{k n}$ is the maximum allowable probability of this water quality constraint violation relative to the required confidence level.
The heads and concentrations at candidate well locations and control points are calculated from groundwater flow and solute transport models, which solve the flow and transport equations. Thus the distributions of head and concentration variables can be expressed as some functions representative of the groundwater flow and solute transport equations solved through MODFLOW and MT3DMS codes.

$\mathrm{P}\left(h_{i}\right)=f^{h i}\left(x_{i}, \mathrm{P}\left(\sigma_{1}\right), \mathrm{P}\left(\sigma_{2}\right), \ldots, \mathrm{P}\left(\sigma_{n}\right)\right)$

$\mathrm{P}\left(c_{k i}\right)=f^{c k i}\left(x_{i}, \mathrm{P}\left(\sigma_{1}\right), \mathrm{P}\left(\sigma_{2}\right), \ldots, \mathrm{P}\left(\sigma_{n}\right)\right)$

$\mathrm{P}\left(h_{m i}\right)=f^{h m}\left(x_{i}, \mathrm{P}\left(\sigma_{1}\right), \mathrm{P}\left(\sigma_{2}\right), \ldots, \mathrm{P}\left(\sigma_{n}\right)\right)$

$\mathrm{P}\left(c_{k n i}\right)=f^{c k n}\left(x_{i}, \mathrm{P}\left(\sigma_{1}\right), \mathrm{P}\left(\sigma_{2}\right), \ldots, \mathrm{P}\left(\sigma_{n}\right)\right)$

where $\mathrm{P}\left(h_{i}\right), \mathrm{P}\left(c_{k i}\right), \mathrm{P}\left(h_{m i}\right)$, and $\mathrm{P}\left(c_{k n i}\right)$ represent the probability distributions of head and concentration variables, and $\mathrm{P}\left(\sigma_{1}\right), \mathrm{P}\left(\sigma_{2}\right), \ldots, \mathrm{P}\left(\sigma_{n}\right)$ represent the probability distributions of a set of aquifer parameters, initial conditions, and source/sink parameters denoted by $\sigma_{1}, \sigma_{2}, \ldots, \sigma_{n}$

The optimal well selection problem formulated above is a strictly non-linear optimisation problem which cannot be approximated to any standard model. Therefore, an appropriate meta-heuristic search method such as simulated annealing or genetic algorithm can be used to solve the problem. In the illustration presented under Results and Discussion, a relatively small scale problem is considered and solved using the in-built solver of MS Excel.

\section{RESULTS AND DISCUSSION}

The proposed well positioning methodology is applicable in residential areas surrounded by potential pollution sources such as agricultural land, waste landfills, industrial zones and factories. Figure 1 illustrates a residential area near the Avissawella city in Sri Lanka where there are several rubber factories and an export processing zone in the neighbourhood. The underlying groundwater catchment, which possibly feeds the river can get contaminated if effluents leak from the factories. Several incidents of groundwater pollution from rubber factories have been identified in the recent past (Kudaligama, 2004; Rodrigo, 2013; Wipulasena, 2014). Positioning of drinking water supply wells in such areas needs scientific methodologies such as proposed in the present study. However, to use the proposed methodology, a groundwater flow and transport model 


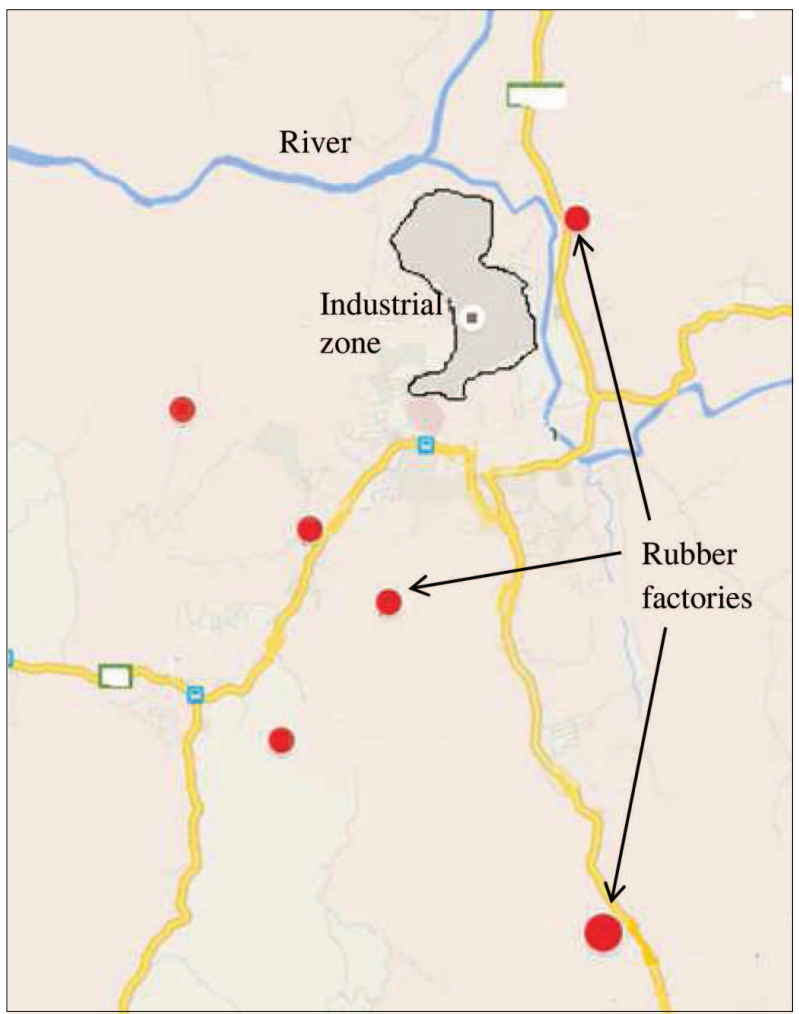

Figure 1: The residential area near Avissawella city of Sri Lanka surrounded by potential pollution sources

(MODFLOW \& MT3D) of the area is required. Since such models are not available for most Sri Lankan aquifers, and the development of hydrological models is beyond the scope of this paper, the performance of the proposed well positioning methodology is illustrated using a small hypothetical case study shown in Figure 2. The results from this case study illustrates the importance of developing hydrological models to be used in such well positioning methodologies.

The proposed simulation-optimisation methodology was applied to select the best extraction well location with a sustainable yield of $150 \mathrm{~m}^{3} /$ day from a set of four candidate locations shown in Figure 2. There are three existing groundwater wells, which are considered as head control locations. The new well should be located so that it does not have extreme negative impacts on the existing wells. A landfill site and two soakage pits from which effluents can leach into the aquifer are also present in the study area. A single groundwater pollutant was considered in this illustration (for example, nitrate is a commonly found pollutant in domestic effluents). With a reasonable level of confidence, the new well should be located beyond the reach of any pollutant coming from those sources of pollution.
The hydro-geological parameters were set so that the head gradients and flow directions are irregular. Fixed head boundaries are present towards the North and South margins of the study area. Hydraulic conductivity varied from 2.0 to $11.5 \mathrm{~m} /$ day. Aquifer top elevation was $10.8 \mathrm{~m}$. Bottom elevation was high along the Western and Eastern edges (about $10-8 \mathrm{~m}$ ) and gradually drops towards the centre line (about $5 \mathrm{~m}$ ).

The aquifer was modelled as a single convertible layer with $25 \mathrm{~m} \times 25 \mathrm{~m}$ cells ( 30 rows and 20 columns). The values of other hydro-geological parameters considered in the MODFLOW and MT3DMS models were, porosity $=0.25$; specific yield $=0.2$; confined storage coefficient $=$ 0.2 ; longitudinal dispersivity $=35 \mathrm{~m}$; ratio of horizontal to longitudinal dispersivity $=0.1$; ratio of vertical to longitudinal dispersivity $=0.01$; and molecular diffusion coefficient $=0$. Only advective and dispersive transport was simulated assuming no chemical reactions. The planning period was set to 30 years.

It was assumed that the pollutant mass loading from the two point sources (soakage pits) are not known, but the maximum possible loading rate was estimated as $0.3 \mathrm{~g} / \mathrm{s}$. Thus the mass loading rate from the two point sources were assumed to be of uniform distribution with lower and upper bounds of 0.0 and $0.3 \mathrm{~g} / \mathrm{s}$, respectively, allowing the possibility of no leaking. The landfill site was modelled as a diffuse source with uncertain leachate concentrations. The landfill leachate concentration was assumed to be normally distributed with a mean of $0.1 \mathrm{mg} / \mathrm{L}$ and a standard deviation of $0.02 \mathrm{mg} / \mathrm{L}$. For simplicity, it was assumed that the water extraction rates from the three existing wells are 150, 100, and $120 \mathrm{~m}^{3} /$ day. The cost of installation and operation was considered as constant despite the location, and then the optimal well locations would be determined by the modelled constraints.

For the optimisation, the maximum acceptable concentration of the concerned constituent was assumed to be $50 \mathrm{mg} / \mathrm{L}$. Hence, the concentrations in the new and existing wells have to be kept below $50 \mathrm{mg} / \mathrm{L}$ with a confidence level of $90 \%$. Thus the probability that the concentration exceeds $50 \mathrm{mg} / \mathrm{L}$ should be kept below $10 \%$. It was assumed that the minimum heads required at the existing well locations 1,2 and 3 to avoid drying out are $8.2 \mathrm{~m}, 8.7 \mathrm{~m}$ and $9.7 \mathrm{~m}$, respectively. The minimum heads required at the candidate well locations $1,2,3$, and 4 to avoid drying out were 9.1, 9.1, 9.4 and 7.3 , respectively.

A summary of the results produced from four Monte Carlo simulations, each with 100 parameter realisations, are given in Table 1. 


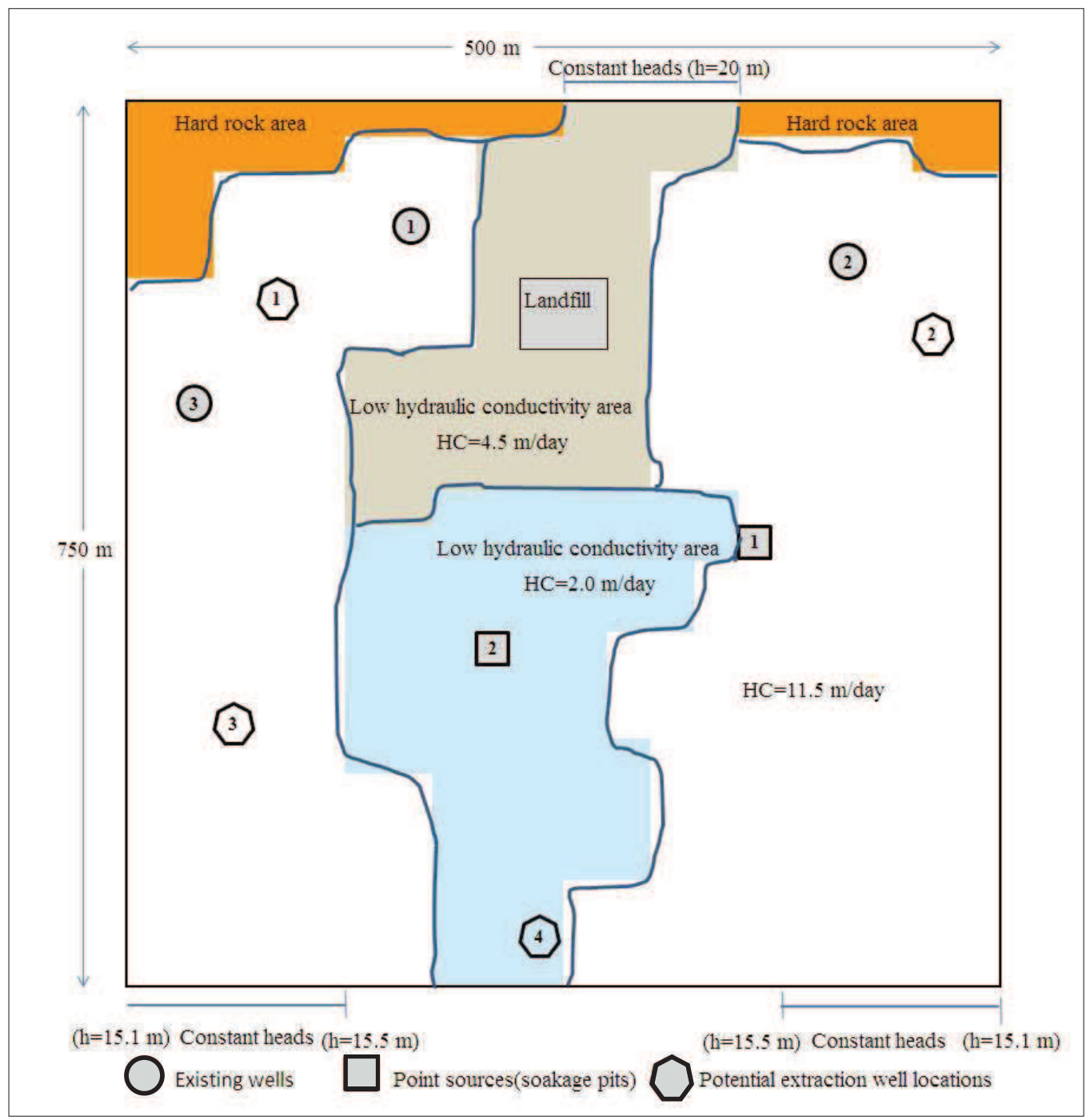

Figure 2: Hypothetical study area

Based on the simulation results in Table 1, the optimal well location selected by the optimisation model was well location 4. Candidate well location 1 has the least likelihood of getting contaminated, although it is located in close proximity to the landfill site. The concentration in location 1 is always below the maximum acceptable level. However, if a new well is installed in location 1 in the neighbourhood of two existing wells, the new well can cause the existing well 3 to dry out. The aquifer thickness is lesser towards the western margin of the aquifer, and thus a new well in near upstream will cause well 3 to dry out. Therefore candidate location 1 is not feasible.

Well location 2 is also not feasible because the probability that the concentration of this new well exceeds the maximum acceptable level of $50 \mathrm{mg} / \mathrm{L}$ is $17 \%(>10 \%)$. Well location 2 is more susceptible to contamination compared to location 1 although location 2 seems to be in the up-gradient of the point sources and further away from the diffuse source (landfill) compared to location 1. Irregular hydraulic gradients and flow directions cause this difference. There are hydraulic gradients from the North to South as well as from the centre line (low hydraulic conductivity area) to the West and East. The gradient from the upper low hydraulic conductivity area towards the eastern margin is steep, and the effluents leaking from the landfill site reach well location 2 . At the same time, the plume originating from point source 1 is wide enough to reach location 2 , making well location 2 vulnerable to pollution and therefore infeasible for the purpose. 
Table 1: A summary of the results from four Monte Carlo simulations

\begin{tabular}{lcccc}
\hline New (potential) well simulated & 1 & 2 & 3 & 4 \\
\hline $\begin{array}{l}\text { Final head at new well itself }(\mathrm{m}) \\
\text { Probability distribution of }\end{array}$ & 12.5 & 12.81 & Dry & 13.23 \\
concentration at the new well itself & & & & \\
Mean & 0.93 & 29.50 & 39.70 & 25.90 \\
Standard deviation & 0.19 & 14.75 & 21.85 & 11.80 \\
Maximum & 1.50 & 56.80 & 79.80 & 53.60 \\
Minimum & 0.40 & 0.90 & 3.90 & 2.60 \\
Instances above 50 mg/L & 0 & 17 & 32 & 6 \\
Final head in existing well 1 & 14.14 & 14.39 & 15.04 & 14.9 \\
Final head in existing well 2 & 15.43 & 14.28 & 15.69 & 15.54 \\
Final head in existing well 3 & Dry & 11.3 & 11.91 & 11.73 \\
\hline
\end{tabular}

Candidate well location 3 is also not feasible in terms of water availability. If a new well is installed in location 3 to extract water at a rate of $150 \mathrm{~m}^{3} /$ day, the well will dry out soon. As mentioned earlier, the aquifer thickness is lesser towards the western boundary of the study area which is heavily unitised by two existing wells upstream. Thus well location 3 is not suitable for the purpose.

The only well location which satisfies all the constraints is location 4 . The probability that the concentration of water at this location exceeds $50 \mathrm{mg} / \mathrm{L}$ is just $6 \%(<10 \%)$. It meets the head constraints also. This location is in a low hydraulic conductivity area and seems to be in the downstream of all pollution sources. However, the hydraulic gradients towards the West and East seem to be steeper than the gradient towards the South, and thus the contaminants flow towards the West and East before reaching the southern margin of the study area. On the other hand, the aquifer thickness along the center line is higher and a large amount of water is available in location 4 although the hydraulic conductivity is lesser. Thus the only feasible solution, and hence the optimal extraction well location is location 4, despite the associated costs.

This result highlights the importance of using simulation in the selection of optimal well locations. Simulation provides valuable information such as the flow directions, which could not have been observed from site inspection or data analysis. The problem discussed above is a small illustrative example (with just four decision variables and a few constraints) for which the optimal solution can be easily obtained. However the real world problems can have a large number of candidate well locations and constraints. To solve such complex problems, a meta-heuristic search algorithm will be required.

\section{CONCLUSION}

A simulation-optimisation based methodology was proposed for optimal positioning of groundwater supply wells in residential areas. Several hidden factors such as heterogeneous characteristics of subsurface strata, irregular gradients, and varying aquifer thickness have significant influences on the sustainability of a water supply well. As demonstrated, water supply wells located far away from potential pollution sources and even in the upstream of pollution sources can also get contaminated over time, as heavy withdrawals and sometimes possible changes of inflows can change the head gradients and flow directions. Therefore, potential pollution sources, existing water supply wells, and all applicable environmental constraints should be considered in locating water supply wells to assure a safe and reliable water supply. Given such complexity, an externally linked simulation-optimisation model is shown to be a reliable tool for selecting sustainable locations for water supply wells.

The behaviours of groundwater pollution sources and water withdrawals are usually uncertain, and probabilistic constraints can be imposed to maximise the likelihood of meeting water quality and quantity requirements. This paper demonstrated a methodology for locating water supply wells outside the vicinity of contamination, taking into account the underlying uncertainties. As demonstrated, the proposed methodology provides defendable scientific foresight about the consequences of locating a new well in any potential location.

Such simulation-optimisation based methodologies require hydro-geological information and estimations of future withdrawals and pollution, and associated cost terms. Scientific experiments are required to estimate 
the hydro-geological parameters such as hydraulic conductivity, and it is difficult to predict the behaviour of pollution sources and water withdrawals. Therefore, such methodologies are rarely used in practical situations of locating water supply wells. However, approximate values are sufficient if the uncertainties in these estimates are incorporated into the decision models. It was shown that even with probabilistic estimates of parameters, the proposed methodology can produce decisions, which can be explained and understood based on scientific evidence.

The same approach can be utilised to locate unavoidable pollution sources such as waste landfill sites, minimising the likelihood of negative environmental impacts on existing water supply wells and surface water bodies etc. The work has to be further extended to include proper optimisation algorithms.

\section{REFERENCES}

1. Al-Daghastani N.S. \& Al-Maitah K.J. (2006). Preliminary locations of the groundwater wells using GIS techniques. Proceedings of the ISPRS Commission VII Symposium on Remote Sensing: From Pixels to Processes (eds. N. Kerle $\&$ A. Skidmore), volume 36, Enschede, The Netherlands, 8-11 May.

2. Bandara N.J.G.J. \& Hettiarachchi J.P.A. (2010). Environmental impacts with waste disposal practices in a suburban municipality in Sri Lanka. International Journal of Environment and Waste Management 6(1/2): 107 - 116. DOI: http://dx.doi.org/10.1504/IJEWM.2010.033987

3. Chadalavada S., Datta B. \& Naidu R. (2010). Uncertainty based optimal monitoring network design for a chlorinated hydrocarbon contaminated site. Environmental Monitoring and Assessment 173(1 - 4): 929 - 940.

DOI: http://dx.doi.org/10.1007/s10661-010-1435-2

4. Chang L.C., Shoemaker C.A. \& Liu P.L.F. (1992). Optimal time-varying pumping rates for groundwater remediation: application of a constrained optimal control algorithm. Water Resources Research 28(12): 3157 - 3171.

DOI: http://dx.doi.org/10.1029/92WR01685

5. Chu H.J., Hsiao C.T. \& Chang L.C. (2005). Optimal remediation design in groundwater systems by intelligent techniques. Knowledge-Based Intelligent Information and Engineering Systems 3682: 628 - 634.

DOI: http://dx.doi.org/10.1007/11552451_86

6. Datta B. \& Dhiman S.D. (1996). Chance constrained optimal monitoring network design for pollutants in groundwater. Journal of Water Resources Planning and Management 122(3): 180 - 188.

7. Fazlulhaq N. (2012). Eating out tonight? beware of the water you drink. The Sunday Times, $26^{\text {th }}$ August 2012.

8. Fowler K.R., Kelley C.T., Miller C.T., Kees C.E., Darwin R.W., Reese J.P., Farthing M.W. \& Reed M.S.C. (2004). Solution of a well field design problem with implicit filtering. Optimization and Engineering 5(2): 207 - 234. DOI: http://dx.doi.org/10.1023/B:OPTE.0000033375.33183.e7

9. Harbaugh B.A.W., Banta E.R., Hill M.C. \& McDonald M.G. (2000). MODFLOW-2000, the US Geological Survey Modular Groundwater Model. US Geological Survey, Reston, USA.

10. Hsiao C.T. \& Chang L.C. (2002). Dynamic optimal groundwater management with inclusion of fixed costs. Journal of Water Resources Planning and Management 128(1): $57-65$.

11. International Water Management Institute (IWMI) (2005). IWMI Water Policy Briefing - 14: Planning Groundwater use for Sustainable Rural Development. International Water Management Institute, Colombo, Sri Lanka.

12. Ko N., Lee K. \& Hyun Y. (2005). Optimal groundwater remediation design of a pump and treat system considering clean-up time. Geosciences Journal 9(1): 23 - 31.

13. Kudaligama S. (2004). Effect of rainfall on the pollution problem associated with natural rubber processing: a case study in five factories in the Low Country Wet Zone. Journal of the National Institute of Plantation Management 20(2): $15-18$.

14. Liyanage C.E., Thabrew M.I. \& Kuruppuarachchi D.S.P. (2000). Nitrate pollution in groundwater of Kalpitiya: an evaluation of the content of nitrates in the water and food items cultivated in the area. Journal of the National Science Foundation of Sri Lanka 28(2): 101 - 112.

DOI: http://doi.org/10.4038/jnsfsr.v28i2.2679

15. Mageswaran R. \& Mahalingam S. (1983). Nitrate-nitrogen content of well water and soil from selected areas of the Jaffna Peninsula. Journal of the National Science Council of Sri Lanka 11(2): 269 - 275.

16. Mantoglou A. \& Kourakos G. (2007). Optimal groundwater remediation under uncertainty using multiobjective optimization. Water Resources Management 21(5): $835-847$.

DOI: http://dx.doi.org/10.1007/s11269-006-9109-0

17. Mayer S., Kelley C.T. \& Miller C.T. (2002). Optimal design for problems involving flow and transport phenomena in saturated subsurface systems. Advances in Water Resources 25: $1233-1256$.

DOI: http://dx.doi.org/10.1016/S0309-1708(02)00054-4

18. Nanthini T., Mikunthan T. \& Vijayaratham R. (2001). Some physiochemical characteristics in some (selected) water supply wells in the Jaffna peninsula. Journal of the National Science Foundation of Sri Lanka 29(1 \& 2): $81-95$.

DOI: http://doi.org/10.4038/jnsfsr.v29i1-2.2621

19. Panabokke C.R. (2001). Groundwater management in Sri Lanka. Economic Review 27: 8 - 9.

20. Panabokke C.R. \& Perera A.P.G.R.L. (2005). Groundwater Resources in Sri Lanka. Water Resources Board, Colombo, Sri Lanka.

21. Park C.H. \& Aral M.M. (2003). Optimization of well locations and pumping rates in coastal aquifers. Proceedings of the 2003 Georgia Water Resources Conference, University of Georgia. Athens, Georgia, April 23 - 24. Available at http://gwri.gatech.edu/sites/ default/files/files/docs/2003/Park\%20and\%20Aral.pdf. 
22. Prasad R.K. \& Mathur S. (2008). Potential well locations in in-situ bioremediation design using neural network embedded Monte Carlo approach. Practice Periodical of Hazardous, Toxic, and Radioactive Waste Management 12(4): $260-269$.

23. Rao S.V.N. \& Manju S. (2007). Optimal pumping locations of skimming wells. Hydrological Sciences Journal 52(2): $352-360$.

DOI: http://dx.doi.org/10.1623/hysj.52.2.352

24. Ratzlaff S.A., Aral M.M. \& Al-Khayyal F. (1992). Optimal design of groundwater capture systems using segmental velocity direction constraints. Groundwater 30(4): $607-612$.

DOI: http://dx.doi.org/10.1111/j.1745-6584.1992.tb01537.x

25. Razowska-Jaworek L.K. (2010). The best location for a public supply well - an analysis using a GIS. Proceedings of XXXVIII IAH Congress - Groundwater Quality and Sustainability, Krakow, Poland, 12 - 17 September, pp. 795.

26. Rodrigo M. (2013). DPL's CSR dips as the gloves come off its operations - pollution by industrial effluents, an ever present hazard for those living in the vicinity of factories. The Sunday Times, $11^{\text {th }}$ August 2013.

27. Silva J.F.F.D. \& Haie N. (2007). Optimal locations of groundwater withdrawals in coastal aquifers. Water Resources Management 21(8): 1299 - 1311. DOI: http://dx.doi.org/10.1007/s11269-006-9082-7

28. Storck P.J., Eheart W. \& Valocchi A.J. (1997). A method for the optimal location of monitoring wells for detection of groundwater contamination in three-dimensional heterogeneous aquifers. Water Resources Research 33(9): $2081-2088$
DOI: http://dx.doi.org/10.1029/97WR01704

29. Wang W. \& Ahlfeld D.P. (1994). Optimal groundwater remediation with well location as a decision variable: model development. Water Resources Research 30(5): $1605-1618$

DOI: http://dx.doi.org/10.1029/93WR03552

30. Winston W.L. (1994). Operations Research: Applications and Algorithms, $3^{\text {rd }}$ edition. Wadsworth Publishing Company, Belmont, USA.

31. Wipulasena A. (2014). Hanwella protest a repeat of Rathupaswela? The Sunday Times, $23^{\text {rd }}$ March 2014.

32. Yenigul N.B., Elfeki A.M.M. \& van den Akker C. (2006a). New approach for ground water detection monitoring at lined landfills. Ground Water Monitoring and Remediation 26(2): $79-86$

DOI: http://dx.doi.org/10.1111/j.1745-6592.2006.00073.x

33. Yenigul N.B., Elfeki A.M.M., van den Akker C. \& Dekking F.M. (2006b). A decision analysis approach for optimal groundwater monitoring system design under uncertainty. Hydrology and Earth System Sciences Discussions 3: $27-68$.

DOI: http://dx.doi.org/10.5194/hessd-3-27-2006

34. Zheng C. \& Bennett G.D. (2002). Applied Contaminant Transport Modelling, $2^{\text {nd }}$ edition. John Wiley and Sons Inc., New York, USA.

35. Zheng C. \& Wang P.P. (1999). MT3DMS: a modular threedimensional multispecies model for simulation of advection, dispersion and chemical reactions of contaminants in groundwater systems; documentation and user's guide. Contract Report SERDP-99-1. U.S. Army Engineer Research and Development Centre, Vicksburg, USA. 